\title{
EFFECT OF THE POSITION OF PARALLELOGRAM RIBS IN MICRO-CHANNEL ON HEAT TRANSFER USING DIAMOND NANOPARTICLES
}

\author{
Kamel Chadi ${ }^{1 *}$, Nourredine Belghar ${ }^{1}$, MokhtarFalek ${ }^{2}$, Zied Driss ${ }^{3}$, \\ Belhi Guerira ${ }^{4}$ \\ ${ }^{1}$ Laboratory of Materials and Energy Engineering, University of mohamed khider \\ Biskra, Algeria \\ ${ }^{2}$ University Mohamed Khider of Biskra, Algeria \\ ${ }^{3}$ Laboratory of Electromechanical Systems, National School of Engineers of Sfax \\ (ENIS), University of Sfax, Tunisia \\ ${ }^{4}$ Laboratory of Mechanical Engineering, University of mohamed khider Biskra, Algeria
}

Received 10.07.2020

Accepted 03.09.2020

\begin{abstract}
In the present work, we have studied numerically three dimensions, the impact of the position of parallelogram ribs in a micro-channel on thermal exchange. In this study, we proposed three cases of micro-channel heat sinks with parallelogram ribs. As well as one case without ribs, in each of the three cases, we varied the parallelogram rib positions on the micro-channel. The main purpose of this study is to find the best position for parallelograms ribs in which the heat dissipation is useful for improving the thermal performance of the micro-channel as well as improving the cooling of electronic components. We have chosen silicon micro-channel drains for four cases. Constant heat flux is applied to the bottom surfaces and using a nanofluid diamond-water with 5\% volume concentration of diamond nanoparticle as a coolant. The simulation has been carried out using the commercial software ANSYS-Fluent. Reynolds number (Re) has been taken between 200 and 400 with the corresponding inlet velocity from $1.53 \mathrm{~m} / \mathrm{s}$ to $3.01 \mathrm{~m} / \mathrm{s}$, and the flow regime has been assumed to be stationary. The numerical results show that the parallelogram ribs position of the micro-channel in the second case gave an improvement in heat exchange, where the Nusselt number is higher than in the other cases, and showed a reduction in the temperature of the heated bottom wall compared to the other cases. Also, the micro-channel shape in the second case can be used to cool the electronic components. The results also showed that with increasing Reynolds number $(\mathrm{Re})$, the friction factor of the micro-channel decreases in all cases. At the same time, we
\end{abstract}


find the lowest value of the thermal resistance in the second case and the biggest value in the first case, base micro-channel without ribs.

Keywords: thermal exchange; parallelogram ribs; micro-channel; nanofluid.

\section{Introduction}

The electronics industry has witnessed unmatched growth in recent times. This exponential growth of electronic devices through the miniaturization of electronic components and the increased operating rate has led to problems with its high temperature. To ameliorate this high temperature, it is obligatory to improve the heat exchange and the cooling method of components. The convection heat transfer can be improved in specific engineering of micro-channel by several methods, among them adjusting the geometry, adding the fins as well as changing the physical properties of a liquid used in the cooling process. Among the work in this field, we find that Hongtao et al. [1] numerically studied the influence of the geometric parameters on heat exchange performance and flow of the rectangular, trapezoidal, and triangular cross-sectional formed micro-channel heat sinks. The results confirmed that the form and geometric parameters of micro-channel have a remarkable effect on the flow and heat exchanger characteristics of the micro-channel. Gholami et al. [2] studied numerically the natural flow and thermal exchange in a vertical channel with dimpled fins using $\mathrm{Cu}, \mathrm{CNT}, \mathrm{TiO}_{2}$, and $\mathrm{Al}_{2} \mathrm{O}_{3}$ nanoparticles. In this research, they choose a number Rayleigh number (Ra) between $3.25 \times 10^{7}$ and $\mathrm{Ra}=1 \times 10^{8}$, as their results showed that using $2 \%$ and $4 \%$ of CNT volume fraction give rise to significant thermal exchange. Whereas also the Nusselt number showed a significant improvement when using $\varphi=6 \%$ of $\mathrm{TiO}_{2}$ nanoparticles, also they confirmed that the hot surface temperature decreases with the increase of the Rayleigh number and with an increase in the volume concentration of solid and the type of solid nanoparticles. Moreover, on the other hand, Mashayekhi et al. [3] studied numerically the convective heat exchange of the $\mathrm{H}_{2} \mathrm{O}-\mathrm{Al}_{2} \mathrm{O}_{3}$ nanofluid with volume concentration ranging from 1 to $3 \%$ in an oval channel. In this study, the channel is fitted with two rows of twisted conical strip inserts with various directions relative to each other, leading to three different combinations of the inserts, Counter-Conical inserts, outward Co Conical inserts, inward Co Conical inserts. The bottom wall is placed under a continuous heat source. Their results showed between the three combinations of the twisted conical strip insert, Co-Conical inserts present the biggest values of the thermal exchange coefficient (as about 17\%). They also found that the impact of increasing nanofluid concentration on heat performance is more important, especially during an increase in Reynolds number. Jadhav et al. [4] performed a numerical investigation of the effect of different pin fin shapes (ellipse, circle, square, and hexagon) on microchannel. They concluded that for fin pins at larger height and at high flow coolant inlet velocities, the values of Nusselt number increases. They found that the square pin fins are the best among the studied pin fin shapes in terms of thermal performance. Also, He et al. [5] studied numerically the convective heat exchange of the $\mathrm{H}_{2} \mathrm{O}-\mathrm{Cu}$ nanofluid with a volume concentration of solid $(\mathrm{Cu})$ ranging from 1 to $3 \%$ in a tube with one and with two twisted tapes. In this simulation, the Reynolds numbers (Re) between 3000 and 36,000 . They found that the utilization of one contorted tape is more favorable than two twisted from the thermal-fluid dynamics viewpoint. Another study by Miansari et al. [6] numerically studied the impact of rectangular micro-channel height and Reynolds number 
$(\mathrm{Re})$ on the temperature distribution, pressure drop, and Nusselt number $(\mathrm{Nu})$ of a carboxy-methyl cellulose / $\mathrm{CuO}$ nanofluid with a $1 \%$ volume concentration of the $\mathrm{CuO}$ solid nanoparticle. They used four Reynolds numbers $(\operatorname{Re}=250,500,750$, and 1000) and three different heights of micro-channel $\mathrm{H}=1 \mathrm{~mm}, 1.5 \mathrm{~mm}$, and $2 \mathrm{~mm}$. They found out that increment of channel height and inlet Reynolds number decreases the temperature, while they increment increase heat exchange rate and Nusselt number. Also, Likewise, increasing Reynolds number increment the pressure drop along the micro-channel. Besides, Bouakkaz et al. [7] Numerically investigated the effect of $\mathrm{CuO}$ nanoparticles in improving the total heat transfer around a square cylinder, with different solid volume fractions (0-0.04) and with different nanoparticle diameters $\left(\mathrm{d}_{\mathrm{np}}=30,60\right.$, and $\left.90 \mathrm{~nm}\right)$ for Reynolds number ranged from 10 to 40 . They noted that the average Nusselt number rises with the increases of the volume fraction of $\mathrm{CuO}$ nanoparticle and Reynolds number and falls with raising nanoparticle diameter. Peng et al. [8] studied the impacts of suspending a diverse number of Silver nanoparticles on the flow characteristics of Argon base liquid in a cubic micro-channel. In order to make a boiling flow situation a cubic channel, they applied a constant temperature to the micro-channel walls and imposed the flow of argon with an outer force of $0.002 \mathrm{eV} / \mathrm{A}$. In addition, they used a statistical approach to provide accurate results. They found that make of two, four, and six nanoparticles into the base fluid (Argon) raises the summation of density as much as $67 \%$. Also, they concluded that the investment in preparing the nanofluid by suspending six and four numbers of nanoparticles of silver is applicable, whilesuspending two nanoparticles in the argon fluid is not practical.

On the other hand, Khodabandeh et al. [9] numerically investigated the thermal and mass exchange characteristics of $\mathrm{H}_{2} \mathrm{O}$-silver nanofluid flowing in a spiral thermal exchanger (HX) using the two-phase mixture. The cold side $\mathrm{H}_{2} \mathrm{O}$-silver nanofluid at $\mathrm{T}=$ $305 \mathrm{~K}$ with $5 \%$ of volume fraction, while the hot side of the HX is water at T=343 K and the Reynolds number $(\mathrm{Re})$ ranging from 500 to 2000. In order to explore the heat transfer effectiveness of the heat exchanger, they twisted cold and hot tubes centrally 3.5, 5.5, and 7.5 turns. The results indicated that increasing the volume concentration of nanoparticles, Reynolds number, and the number of turns increases the overall heat exchange coefficient. Also, they indicated that the effectiveness of the HX decreases with rising the Reynolds number, the volume fraction of solid nanoparticles, and turning around because of the pressure drop of the coolant fluid. In addition, among the studies that have been conducted in the field of improving heat transfer, we find Shirani et al. [10] numerically studied the heat exchange of the $\mathrm{Cu}-\mathrm{H} 2 \mathrm{O}$ nanofluid with a volume concentration of solid between 0 and 0.03 in a lid-driven square cavity in the existence of four rotating cylinders of the Reynolds number ( $\mathrm{Re}$ ) between 86.2 and 862 and Richardson number between 0.1 and 10. Among the results that this study showed that the heat exchange affected by the inertial force, buoyancy force, and changing in thermo-physical properties of the base fluid (water), also as that increasing the concentration of solid nanoparticles in a base fluid improved the thermo-physical properties of the fluid. In a similar attempt, Mehdi et al. [11] studied investigated the heat exchange and $\mathrm{Cu}-\mathrm{H}_{2} \mathrm{O}$ nanofluid flow with volume concentration ranging from 0 to $4 \%$ in an open system enclosure containing a heated obstacle. They studied the impact of the positions of both obstacles and liquid flow outlet in the flow field and heat exchange within the enclosure. During this investigation, the Richardson number going from 0.1 to 10 . They found that the obstacle and outlet position, as well as the Richardson number greatly impact the flow field and heat exchange rate, 
and furthermore heat exchange rate is higher when the obstacle is placed close to the inlet flow and outlet compared to the center of the enclosure. Also, Jamali et al. [12] studied heat exchange characteristics in the flow of water/CuO and water/alumina nanofluid inside a tube with different entrances in the transition regime ( $\operatorname{Re}=500$ to 13000$)$. They studied the impact of the entrance, nanoparticle type, diameter of nanoparticles, concentration of nanoparticles, and Reynolds number. The results showed that the convective heat exchange coefficient and Nusselt number of the base fluid and the nanofluid increase with increasing Reynolds number. In addition, the rate of the rise in the heat transfer coefficient varies according to the type of nanoparticles diameter and volume fraction. Also, they showed that the local Nusselt number and local convective heat exchange coefficient slightly reduce with increasing solid particle diameter at a constant volume concentration of solid nanoparticles.

Abasi et al. [13] studied the hydrodynamics and heat exchange coefficients in a straight micro-tube heat sink and alumina-water nanofluid at different concentrations of solid nanoparticle (alumina) $0,1 \%$, and $2 \%$ using CFD analysis. In this study, the work was divided into two parts. In the first part, the single-phase and two-phase approaches were used to model the heat transfer of water and alumina-water nanofluid in a straight micro-tube. They compared the experimental data with simulation results. They found their results consistent with experimental measurements. While in the second part, the impact of rib and geometry in micro-tubules on the friction factor and Nusselt number $(\mathrm{Nu})$ are studied. They found that spiral pitch increment increases heat performance by an average of $19.8 \%$. It is also better performance is obtained for the ribs height $1 \mathrm{~mm}$ and the pitch $1.5 \mathrm{~mm}$.

Pourfattah et al. [14] studied in 3D the fluid flow in a channel, using multi-walled carbon nanotubes (MWCNT) - aqueous nanofluid with an MWCNT nanoparticle concentration ranging from $0-0.16$ vol. $\%$ and vertical twisted tapes in heat transfer. Reynolds number they chose between 5000 and 25000, and they also chose a set of parameters: the number of vertical twisted bars $(5-10)$, the torsion angle $\left(180-720^{\circ}\right)$, and the angle of the bars attack Twisted $\left(50-130^{\circ}\right)$. In this study, they used a genetic algorithm (GA) and compared it to CFD, and it gave similar results. Among the results that they obtained at Re of 8000 and volume concentration of $0.16 \mathrm{vol} \%$. The maximum heat exchange with the lowest pressure drop occurred on the channel with nine twisted tapes (at the attack angle of $90^{\circ}$ and the twisted angle of $540^{\circ}$ ).

He et al. [15] numerically investigated in laminar flow with an $\left(\mathrm{Al}_{2} \mathrm{O}_{3}-\mathrm{Cu} / \mathrm{H}_{2} \mathrm{O}\right)$ hybrid nanofluid as a working liquid in a designed double-layered small channel is designed with wavy walls. The results indicate that by increasing the flow velocity, using hybrid nanofluids, and changing the fluid flow route geometry (the wavelength of the sinusoid) can improve the maximum temperature distribution and also improve the Nusselt number. A lower Reynolds number $(\mathrm{Re}=50)$ also ameliorates the mixing between fluid and surface on the sinusoidal wavelength across the micro-channel. In another study Bazdar et al. [16] studied in turbulent flow the impact of a sinusoidal wavelength of micro-channel and $\mathrm{CuO}$ nanoparticle volume fraction on flow and heat exchange properties. Reynolds numbers used in this simulation are 3000-4500-6000 and 7500 , with volume concentrations of $0,1.5$, and $3 \%$. They found that the flux with Reynolds number $\mathrm{Re}=7500$ increases the Nusselt number up to $90 \%$ with a volume concentration of $3 \%$, indicating the impacts of heat exchange with the decrease in pressure caused by the nanoparticles. They also found that the change in wavelength leads 
to an increase in heat exchange. For this reason, they recommend using nanoparticles in a sinusoidal micro-channel.

Thus, the main objective of this study is to find appropriate engineering for the micro-channel to improve the cooling of electronic components as well as improving the thermal performance of the micro-channel, by changing the shape of the micro-channels geometry by adding wavy walls on the distance $2 / 3 \mathrm{~L}$ (L: micro-channel length) from the micro-channel exit. Also, the wave shape walls of the micro-channel help dissipate heat.

To further improve the thermal performance, Diamond-water nanofluid was used with a concentration of 0.05 . By studying three different cases in order to find the best position for parallelograms ribs in which the heat dissipation is suitable and contributes to increasing the thermal performance of the micro-channel.

\section{Thermo-physical properties of nanofluid}

The calculation formula of the thermophysical properties of the nanofluids used in our work is considered in this section. The effective thermal conductivity of the nanofluid $\left(k_{n f}\right)$ is approximated by Maxwell-Granetts [17] as follows:

$$
k_{n f}=\frac{k_{s}+2 k_{f}-2 \varphi\left(k_{f}-k_{s}\right)}{k_{s}+2 k_{f}+\varphi\left(k_{f}-k_{s}\right)} k_{f}
$$

Where $k_{s}, k_{f}$, and $\varphi$ are the thermal conductivity of the solid, the thermal conductivity of the fluid (water), and volume fraction, respectively.

The dynamic viscosity $\left(\mu_{n f}\right)$ is approximated by Brinkman model [17] as follows:

$$
\mu_{n f}=\frac{\mu_{f}}{(1-\varphi)^{2,5}}
$$

Where $\mu_{f}$ is the dynamic viscosity of coolant.

The density of the nanofluid $\left(\rho_{n f}\right)$ is given as[18]:

$$
\rho_{n f}=(1-\varphi) \rho_{f}+\varphi \rho_{S}
$$

Where $\rho_{f}$ and $\rho_{s}$ are the density of the fluid and the solid al. [18]:

The heat capacitance of the nanofluid $\left(C p_{n f}\right)$ is expressed as given by Khanafer et

$$
\left(\rho C_{P}\right)_{n f}=(1-\varphi)\left(\rho C_{P}\right)_{f}+\varphi\left(\rho C_{P}\right)_{S}
$$

Where $C_{p}$ is the specific heat of the fluid. table 1 .

The thermophysical properties of pure fluid and nanoparticles are presented in

Table 1. Thermophysical properties of the water and nanoparticles. 


\begin{tabular}{llllll}
\hline & $\rho\left(\mathrm{kg} / \mathrm{m}^{3}\right)$ & $\begin{array}{l}\mathrm{C}_{\mathrm{P}} \\
\left(\mathrm{Jkg}^{-1} \mathrm{~K}^{-1}\right)\end{array}$ & $\begin{array}{l}\mathrm{k} \\
\left(\mathrm{Wm}^{-1} \mathrm{~K}^{-1}\right)\end{array}$ & $\begin{array}{l}\mu \\
(\mathrm{kg} / \mathrm{m} \cdot \mathrm{s})\end{array}$ & References \\
\hline Water (base fluid) & 998.2 & 4182 & 0.613 & 0.001003 & {$[19]$} \\
Diamond nanoparticles & 3500 & 509 & 2300 & - & {$[20]$} \\
\hline
\end{tabular}

\section{Geometries of system}

The geometries of the system are represented in Figure 1 by the commercial ANSYS fluent. It is based on the micro-channel heat sinks (MCHS) of one case. The MCHS of case 1 consists of 20 micro-channels are arranged on a substrate with a bottom area of $10 \times 5 \mathrm{~mm}$.

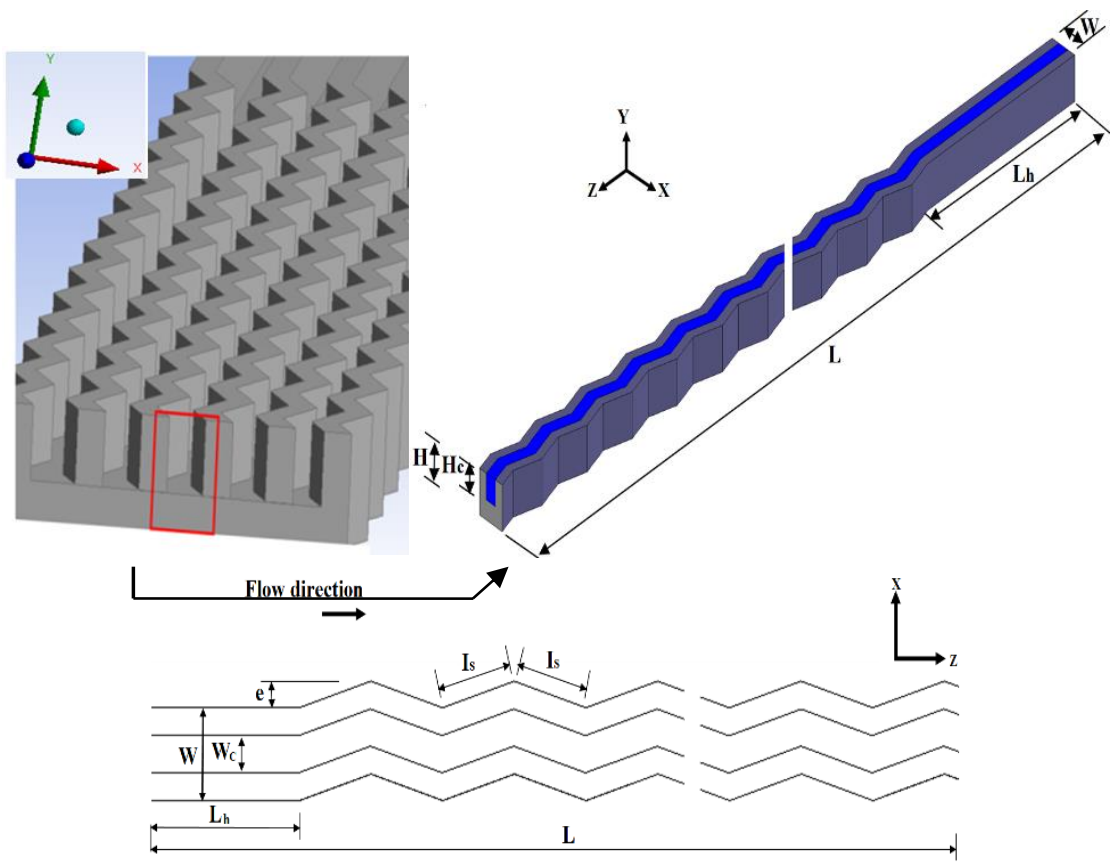

Fig. 1. CAD model of the micro-channel heat sink of case 1.

Heat supplied to the silicon MCHS substrate through a bottom surface where the electronic chips are attached. The heat flux generated by the chips equal $\mathrm{Q}=100 \mathrm{~W} / \mathrm{cm}^{2}$, and thermal insulation on all outside faces of the heat sinks are considered. Due to the symmetry, we have considered only the single of the micro-channel each case, as presented in Figure 1, each micro-channel has a length $L$, a width $W_{c}$, and a height $H_{c}$. The major purpose of this study is to determine the effect of the position of parallelogramribs on the thermal exchange. For this purpose, we schemed three different cases, shown in Figure 2. The geometry parameters of the studied cases are given in Table 2 .

Table 2. Geometrical dimension of the studied cases. 


\begin{tabular}{lccccccccc}
\hline & $\begin{array}{c}\mathrm{L} \\
(\mathrm{mm})\end{array}$ & $\begin{array}{c}\mathrm{H} \\
(\mathrm{mm})\end{array}$ & $\begin{array}{c}\mathrm{W} \\
(\mathrm{mm})\end{array}$ & $\begin{array}{c}\mathrm{H}_{\mathrm{c}} \\
(\mathrm{mm})\end{array}$ & $\begin{array}{c}\mathrm{W}_{\mathrm{c}} \\
(\mathrm{mm})\end{array}$ & $\begin{array}{c}\mathrm{I}_{\mathrm{s}} \\
(\mathrm{mm})\end{array}$ & $\begin{array}{c}\mathrm{L}_{\mathrm{h}}=\mathrm{L} / 3 \\
(\mathrm{~mm})\end{array}$ & $\begin{array}{c}\mathrm{W}_{\mathrm{r}} \\
(\mathrm{mm})\end{array}$ & $\begin{array}{c}\mathrm{e} \\
(\mathrm{mm})\end{array}$ \\
\hline $\begin{array}{l}\text { case 1 } \\
\text { case 2, case 3, } \\
\text { case 4 }\end{array}$ & 10 & 0.35 & 0.25 & 0.20 & 0.10 & 0.26 & 3.33 & $/$ & 0.07 \\
\hline
\end{tabular}
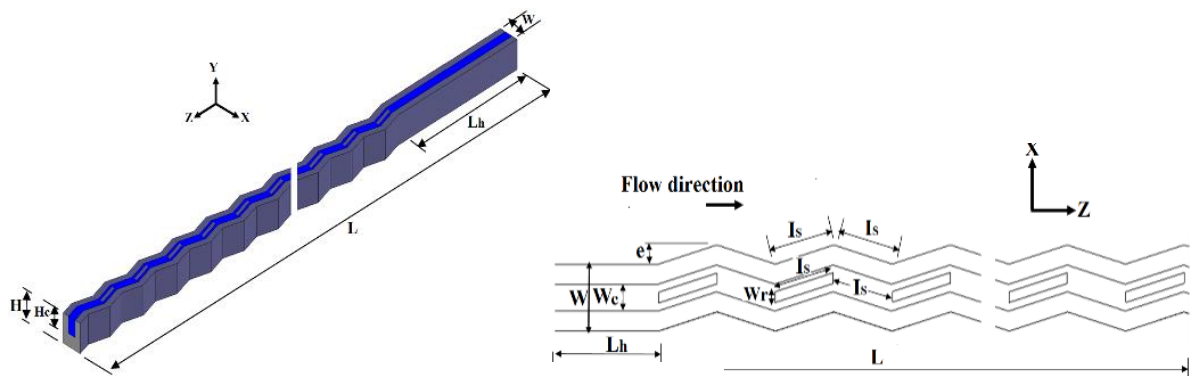

(b) case 2

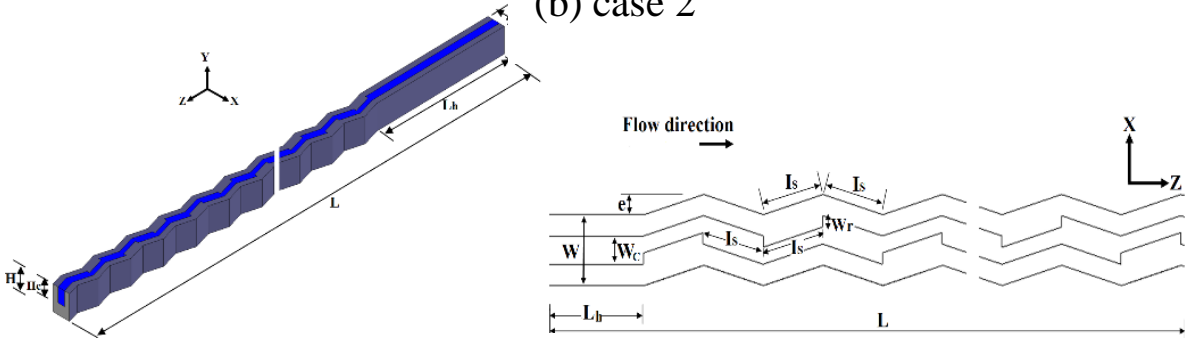

(c) case 3
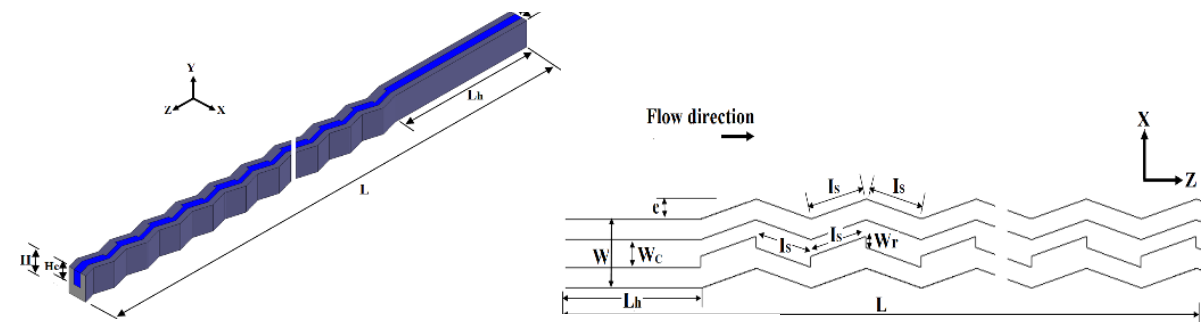

(d) case 4

Fig. 2. Studied cases of the micro-channel heat sinks.

(a) Case 1: the micro-channel is without ribs. We added wavy walls on the distance $\mathrm{z}=6.67 \mathrm{~mm}$ from the micro-channel outlet.

(b) Case 2: based on case 1, we added parallelogram shape ribs (13 ribs) at the centerline along $\mathrm{z}=6.67 \mathrm{~mm}$ from the micro-channel outlet.

(c) Case 3: based on case 2, we placed thirteen parallelograms ribs on the sidewalls of the micro-channel with a length of $\mathrm{z}=6.67 \mathrm{~mm}$ from the outlet of the micro-channel. 
(d) Case 4: based on case 2, we changed the position of the ribs (13 parallelogram shape ribs) to one sidewall of the micro-channel along $\mathrm{z}=6.67 \mathrm{~mm}$ from the outlet of the micro-channel.

\section{Mathematical formulation}

In this study, we supposed that the flow is stationary. The considered diamondwater nanofluidis supposed to be Newtonian, laminar, and incompressible ( $\rho=$ constant). The thermo-physical properties of diamond-water nanofluid are constant. The heat transfer by radiation is considered negligible.

The boundary conditions at the inlet are written as follows:

$$
u=v=0 \quad w=w_{\text {inlet }}=\text { constant } T=T_{\text {inlet }}=\text { constant }
$$

where $u, v$, and $w$ are the velocity components in $x$-axis, $y$-axis, and the $z$-axis, respectively.

- At the outlet, we can write: the gauge pressure is zero

- At the walls of the micro-channel, we can write:

$$
u=v=w=0, T=T_{\text {wall }}
$$

- At the fluid-solid interface, the continuity of the heat flux at the interface between the solid and the fluid is implemented using this formula:

$$
k_{s}{\frac{\partial T}{\partial n_{\text {wall }}}}=k_{f} \frac{\partial T}{\partial n_{\text {wall }}}
$$

Where $\mathrm{n}$ is the outer normal coordinate at the interface between the wall and liquid.

- No-slip boundary conditions are applied to all cases of micro-channel walls

- Constant heat flux is applied to the bottom wall.

- The top wall of micro-channels is assumed to be adiabatic.

Equations are governed by the continuity equation, momentum equation, energy conservation equation, and the equation of the solid [21], which are derived from fundamental principles of heat and fluid flow.

The continuity of the equation is written as follows:

$$
\frac{\partial u}{\partial x}+\frac{\partial v}{\partial y}+\frac{\partial w}{\partial z}=0
$$

- $\quad$ The momentum equations along the $x$-axis, the $y$-axis, and the $z$-axis are written as follows:

$x$-axis: 


$$
u \frac{\partial u}{\partial x}+v \frac{\partial u}{\partial y}+w \frac{\partial u}{\partial z}=\frac{1}{\rho_{n f}}\left[-\frac{\partial P}{\partial x}+\mu_{n f}\left(\frac{\partial^{2} u}{\partial x^{2}}+\frac{\partial^{2} u}{\partial y^{2}}+\frac{\partial^{2} u}{\partial z^{2}}\right)\right]
$$

$y$-axis:

$$
u \frac{\partial v}{\partial x}+v \frac{\partial v}{\partial y}+w \frac{\partial v}{\partial z}=\frac{1}{\rho_{n f}}\left[-\frac{\partial P}{\partial y}+\mu_{n f}\left(\frac{\partial^{2} v}{\partial x^{2}}+\frac{\partial^{2} v}{\partial y^{2}}+\frac{\partial^{2} v}{\partial z^{2}}\right)\right]
$$

z-axis:

$$
u \frac{\partial w}{\partial x}+v \frac{\partial w}{\partial y}+w \frac{\partial w}{\partial z}=\frac{1}{\rho_{n f}}\left[-\frac{\partial P}{\partial z}+\mu_{n f}\left(\frac{\partial^{2} w}{\partial x^{2}}+\frac{\partial^{2} w}{\partial y^{2}}+\frac{\partial^{2} w}{\partial z^{2}}\right)\right]
$$

where $\rho_{n f}, \mu_{n f}$, and $P$ are the density, dynamic viscosity, and the pressure of the nanofluid, respectively

- The energy equation is written as follows:

$$
u \frac{\partial T}{\partial x}+v \frac{\partial T}{\partial y}+w \frac{\partial T}{\partial z}=\alpha_{n f}\left(\frac{\partial^{2} T}{\partial x^{2}}+\frac{\partial^{2} T}{\partial y^{2}}+\frac{\partial^{2} T}{\partial z^{2}}\right)
$$

Where $T$ is the temperature of the nanofluid, $\alpha_{n f}$ is the thermal diffusivity of the nanofluid.

- The heat conduction through the solid wall

$$
\frac{\partial^{2} T_{S}}{\partial x^{2}}+\frac{\partial^{2} T_{S}}{\partial y^{2}}+\frac{\partial^{2} T_{S}}{\partial z^{2}}=0
$$

The average heat transfer coefficient of the micro-channels is determined by the following. (14) [21, 22]:

$$
h_{a v}=\frac{Q}{N A_{w}\left(T_{w}-T_{m}\right)}
$$




$$
N u=\frac{h_{a v} D_{h}}{k_{n f}}
$$

where $A_{w}, T_{w}, N, k_{n f}, T_{m}, Q$ are the convection heat exchange area, the average temperature of wall, number of micro-channels, fluid thermal conductivity, the average temperature of fluid, and heat flux dissipated in the chip, respectively.

where $N u, D_{h}$ are the Nusselt number and the hydraulic diameter, respectively.

Reynolds number is defined as [22]

$$
R e=\frac{\rho_{n f} \cdot w \cdot D_{h}}{\mu_{n f}}
$$

The average fanning friction factor is calculated by the following equation [23]

$$
f=\frac{\left(P_{\text {in }}-P_{\text {out }}\right) D_{h}}{2 \rho_{n f} \cdot w^{2} \cdot L}
$$

Where $\left(p_{\text {in }}-p_{\text {out }}\right)$ and $L$ are the difference between the inlet pressure and outlet pressure and the length of micro-channel, respectively

The thermal resistance of the heat sink is calculated by [22]:

$$
R_{t h}=\frac{T_{\max }-T_{i n}}{Q}
$$

\section{Validation of the results}

To validate our numerical results that were obtained by simulations, we compared them with those of Chai et al. [24]

Figure 3 represents the variation of the Nusselt number $(\mathrm{Nu})$ according to the Reynolds number ranging from 200 and 800 in the rectangular micro-channel, and it also represents a comparison between the experimental results of Chai et al. [24] and our numerical results, we notice that the values of the Nesselt number increase with the increase in the flow velocity. Our results show a good agreement with the results of Chai et al. 


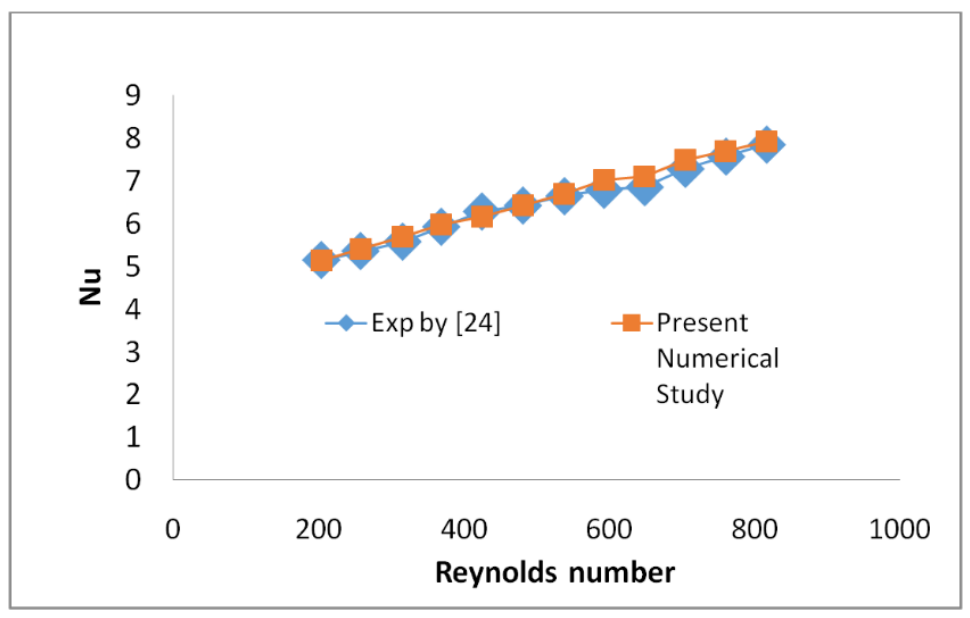

Fig. 3. Comparison of our numerical results with resultants of ref [24].

\section{Results and interpretations}

\section{Grid independence}

The independence of the mesh was tested as shown in Figures (4.a) and (4.b), which show the effect of the number of nodes used for the values of the Nusselt number $(\mathrm{Nu})$, as well as on the values temperature in the micro-channel of case 1 . We notice in Figure (4.a) that the value of the Nusselt number remains stable when the number of nodes is 300000 reached and does not change when the number of nodes increases to 1000000 . While the temperature values (Figure (4.a)) remain variable until the number of nodes is 300000 , it remains constant as the number of nodes increases.

According to these Figures 4.a and 4.b, we conclude that the solution is mesh independent.

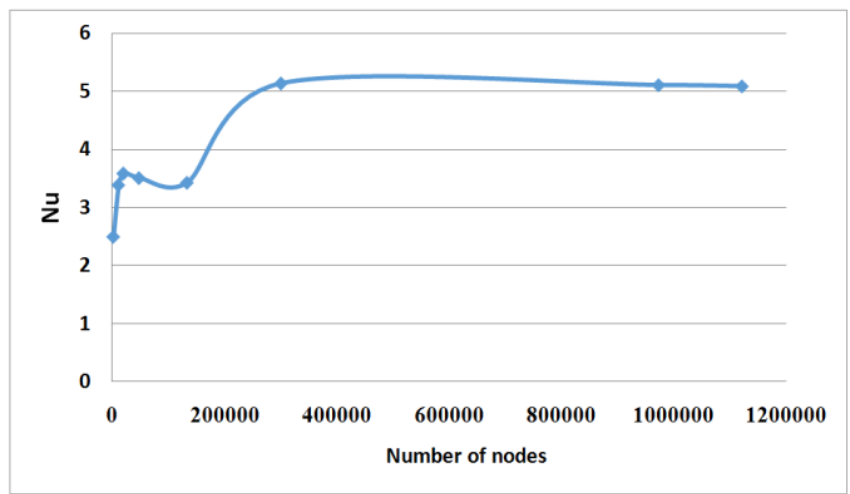




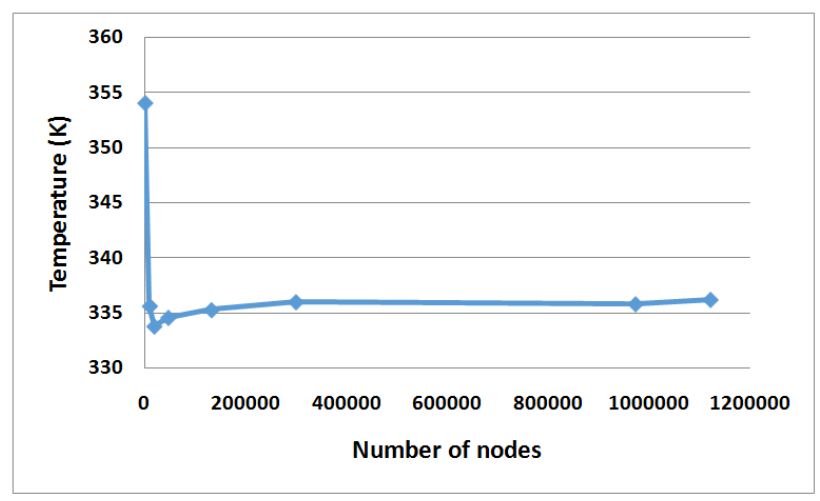

(b)

Fig. 4. Grid independence examination at $R e=200$, and the heat flux is $100 \mathrm{~W} / \mathrm{cm}^{2}$.

ANSYS FLUENT was used to solve governing equations, which depends on the finite volume method (FVM) in solving them, and the finite volume method depends on the spatial integration of conservation equations on finite control volumes, which transforms the governing equations into a set of algebraic equations where they are solved. The SIMPLE algorithm was used to implement pressure-velocity coupling.

The under-relaxation factors used in this study are 0.3 and 0.7 for pressure and for momentum conservation, respectively. The residuals for the velocity components and continuity equation were in the order of $10^{-5}$, and for the temperature field, they were in the order of $10^{-6}$, and the second-order upwind scheme.

After convergence of calculating the simulation, the results are represented as follows:

\section{Temperature distribution}

Figure 5 shows the variation of the temperature on the heated bottom wall for the different cases studied. From these results, we noticed that the temperature profile decreases on the side of the inlet and that it continues to rise until $\mathrm{z}=2.5 \mathrm{~mm}, \mathrm{z}=2.75$ $\mathrm{mm}$, and $\mathrm{z}=3 \mathrm{~mm}$ from the inlet of micro-channel in the case 2 , case 3 and 4 , and case 1 , respectively. 


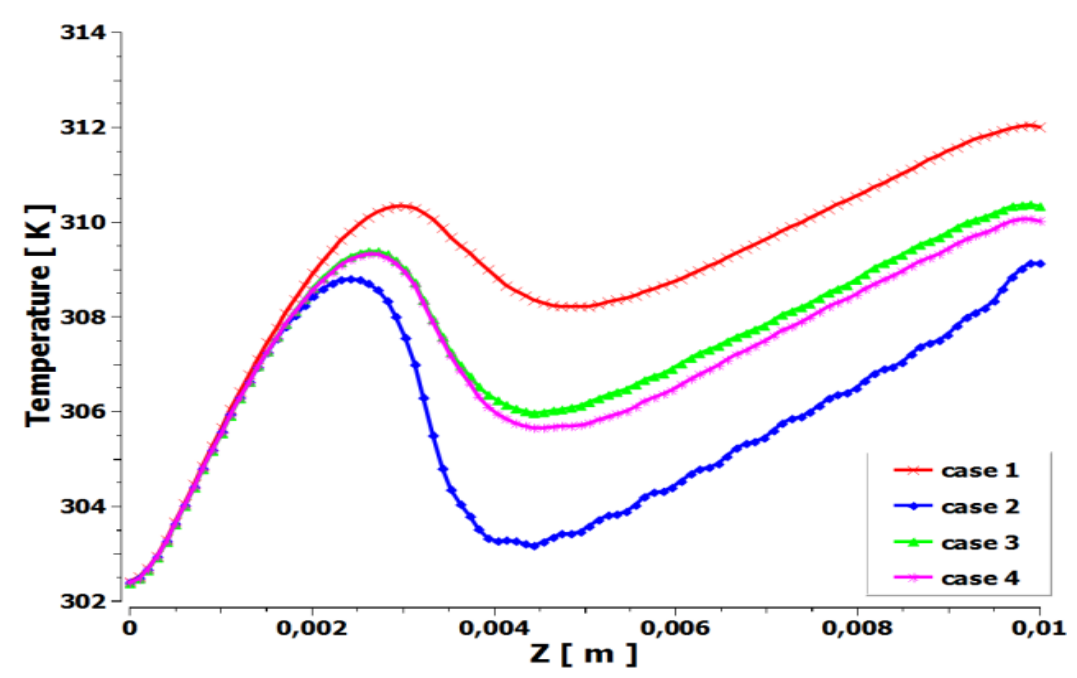

Fig. 5. Comparisons of temperature profiles on the heated bottom wall for all cases at $R e=400$, and the heat flux is $100 \mathrm{~W} / \mathrm{cm}^{2}$.

Then it gradually decreases to a distance of $\mathrm{z}=4.5 \mathrm{~mm}$ from the entrance of the micro-channel, due to the presence of ribs and wavy walls that contribute to a decrease in the temperature and then rises again to the exit of the micro-channel and we note the temperature values of the bottom surface of the substrate in the second case low compared to other cases. Also, we find that the temperature of the lower surface of the channel in the first case is high compared to other cases, and this is because it does not contain the ribs as shown in Figure 6, which shows the temperature distribution on the bottom surface of the substrate for all cases.

The results of Figure 7 show the evolution of the maximum temperature on the bottom wall of the substrate with an inlet Reynolds number $(\mathrm{Re})$ in four cases. The maximum temperature on the bottom wall of the substrate decreases substantially in all cases when the Reynolds number increases. We find the maximum temperature values of the bottom wall of a substrate in case 1 higher than the rest of the cases, i.e., when the Reynolds number changes between 200 to 400, the temperature is in the range of 324.38 to $312.04 \mathrm{~K}$, while in the same range of changing Reynolds number we find the maximum temperature of the substrate in the second case is low, ranging from 319.73 to $309.16 \mathrm{~K}$. At the same time, we find the maximum temperature values for a substrate in the third and fourth cases between 321.56 to $310.37 \mathrm{~K}$ and from 321.28 to $310.06 \mathrm{~K}$, respectively. 
(a)

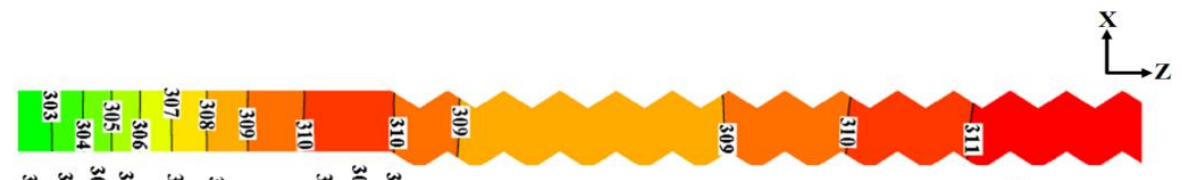

(b)

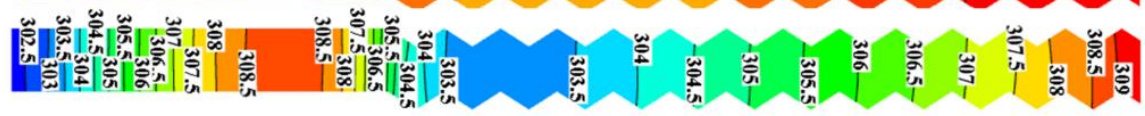

(c)

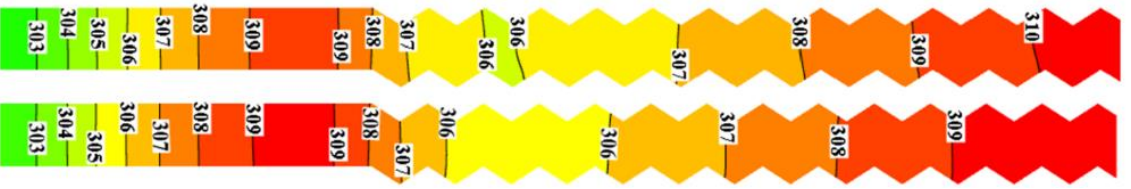

Fig. 6. The two-dimensional of the temperature distribution on the bottom wall for four cases (a: case 1, b: case 2, c: case 3 and $d$ : case 4), at $\operatorname{Re}=400$ and $\varphi=0.05$, the unit of temperature is Kelvin.

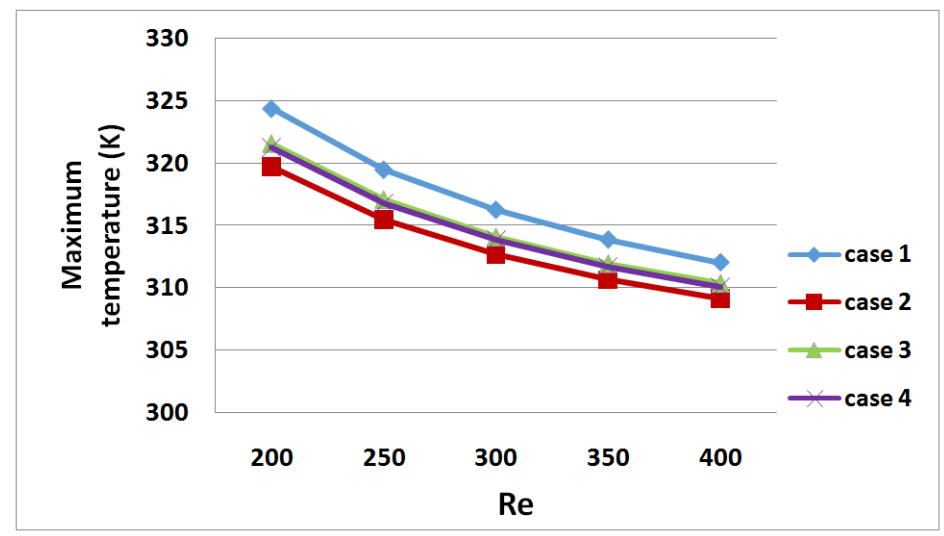

Fig. 7. The maximum temperature on the heated bottom wall with the inlet Reynolds number ranging from 200 to 400 for all cases.

Figure. 8 shows the static temperature contours for plane $y=0.25 \mathrm{~mm}$ along the length of the micro-channel for four cases at Reynolds number (Re) equal to 600 and volume fraction (Diamond) equal to $5 \%$. In case 1, the temperature gradient for diamond/water nanofluid rises along with the longitudinal $\mathrm{z}$ orientation from the microchannel inlet to the outlet due to convection heat exchange.

Comparing the four cases, we find that the effect of the wavy walls in the first case, as well as the effect of the ribs in the three cases (case 2, case 3, and case 4) on the temperature distribution, are noticeable and different even though the three cases have the same number of ribs, and the reason is due to The effect of the position of the ribs inside the channel. In addition to the above, we find that in the second case, it has the lowest temperature values. 


\section{Temperature $[\mathrm{K}]$}

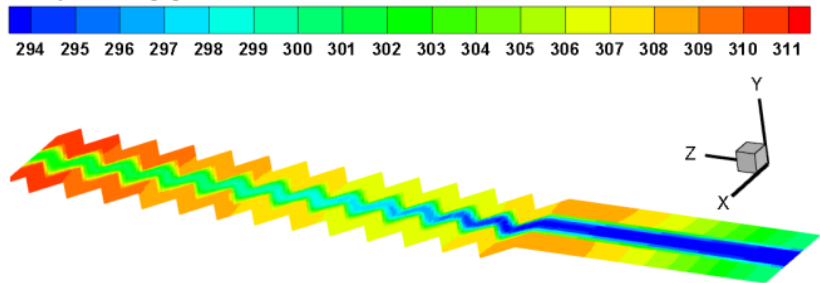

(a) Case 1

Temperature $[\mathrm{K}]$

$\begin{array}{lllllllllllllll}294 & 295 & 296 & 297 & 298 & 299 & 300 & 301 & 302 & 303 & 304 & 305 & 306 & 307 & 308\end{array}$

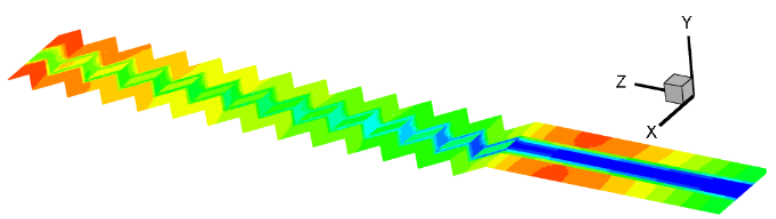

(b) Case 2

Temperature [K]
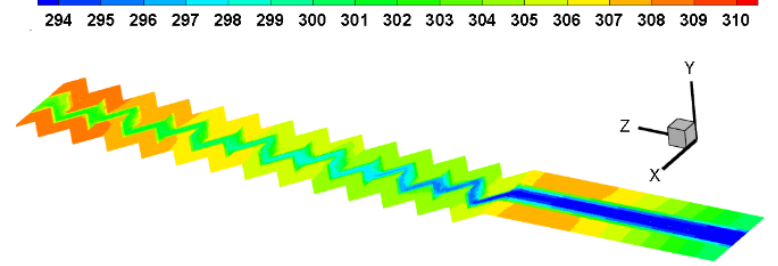

(c) Case 3

Temperature $[\mathrm{K}]$

$\begin{array}{llllllllllllllll}294 & 295 & 296 & 297 & 298 & 299 & 300 & 301 & 302 & 303 & 304 & 305 & 306 & 307 & 308 & 309\end{array}$

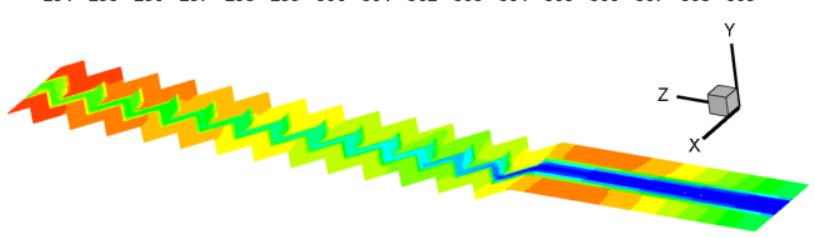

(d) Case 4

Fig. 8. Static temperature contours for plane $y=0.25 \mathrm{~mm}$ along the length of the microchannel for four cases. 


\section{Thermal resistance}

Figure 9 shows the evolution of the thermal resistance with Reynolds number between 200 and 400 in four different cases for the micro-channels. We found that the value of the thermal resistance decreases when the flow velocity increases, and we find the highest value of the thermal resistance in the micro-channel for the first case $\left(R_{t h}=\right.$ $0.63)$ at $R e=200$ we also find it low in the micro-channel for the second case $\left(R_{t h}=0.32\right)$ at $\mathrm{Re}=400$. At the same time, we find that the thermal resistance values in the third and fourth cases are close between them and equal $R_{\text {th }}=0.34$ at $\mathrm{Re}=400$.

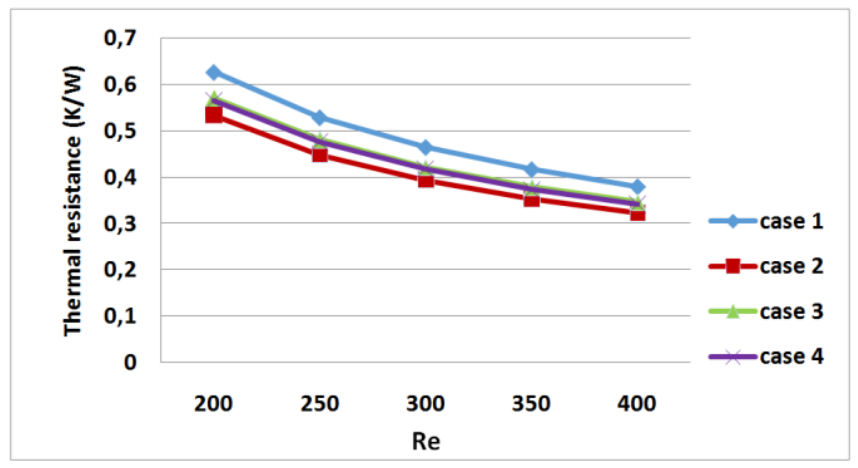

Fig. 9. Variation of thermal resistance with different inlet Reynolds number for all cases.

\section{Heat transfer coefficient and Nusselt number}

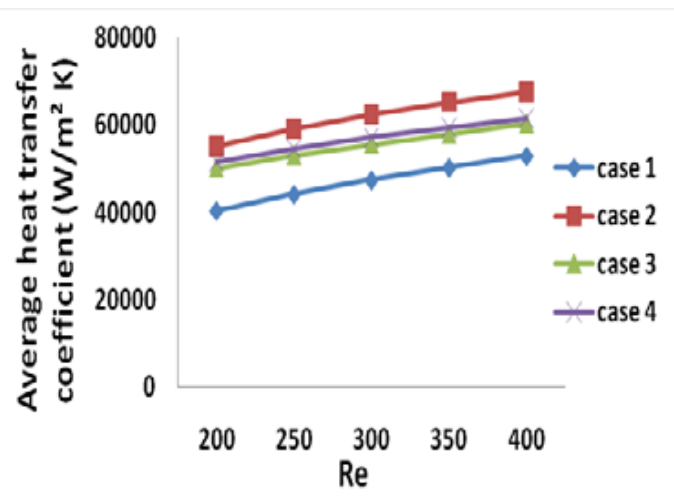

Fig 10. Average heat transfer coefficient of micro-channel heat sinks with the inlet Reynolds number for all cases. 


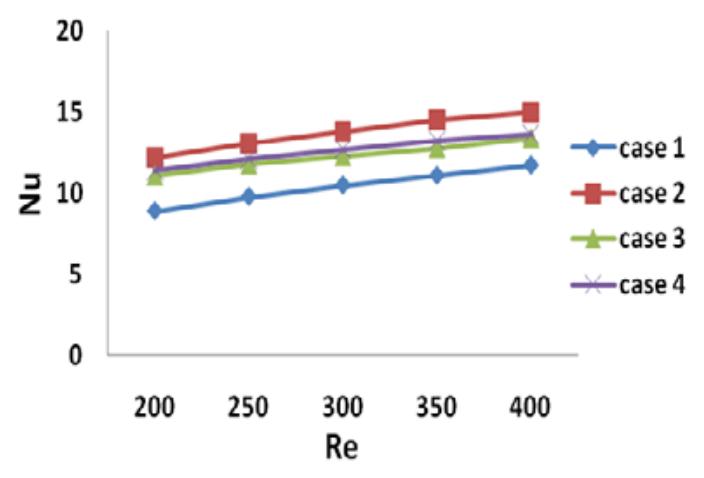

Fig 11. Variation of number Nusselt with inlet Reynolds number for all cases.

Figure 10 shows the average heat transfer coefficient calculated as a function of the inlet Reynolds number in a volume fraction of 0.05 and in all cases. The average heat transfer coefficient is proportional to the Reynolds number (Re) varying from 200 to 400. Comparing between four micro-channel heat sinks the case 2 has the highest values among the four cases, as that the micro-channel heat sinks in the second case gives a better average heat exchange coefficient than case 3 , and case 3 is better than case 2 and case 1. It is found that, in all cases, the average heat exchange coefficient increases linearly with the inlet Reynolds number. The same thing is observed in Figure 11, the Nusselt number $(\mathrm{Nu})$ with a Reynolds number of different cases, the rise in Nusselt number with the inlet Reynolds number. The reason is that when the velocity is increased, the flow rate of the fluid is increased as well, so its ability to remove heat is larger. Also, changing the position of parallelogram ribs in the micro-channel contributes to increased heat exchange between coolant and walls of micro-channel heat sinks. In as shown in Figure 6, we found that the position of the selected parallelogram ribs in the second case is the best in the process of improving the heat exchange.

\section{Friction factor}

In Figure 12, the evaluation of the average friction factor with Reynolds number for four cases studied. The results show that the average friction factor was lowering with the raise of the Reynolds number $(\mathrm{Re})$ inthe different cases of micro-channels. 


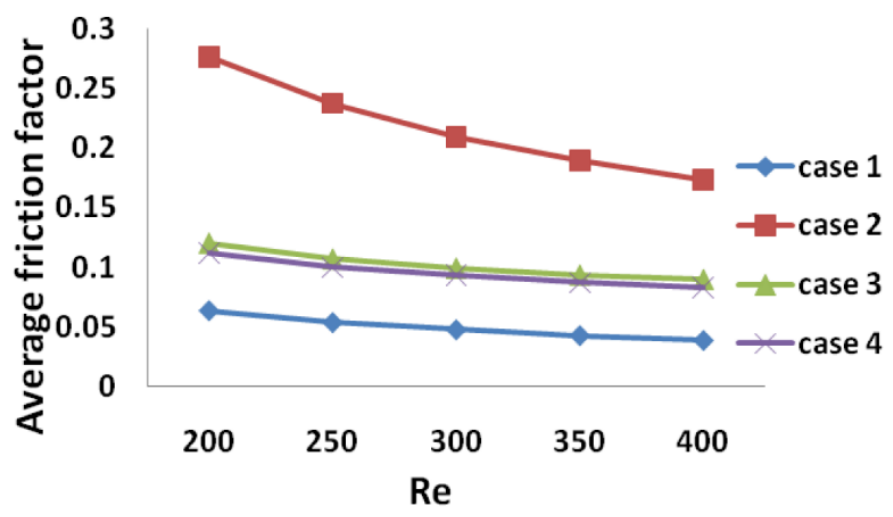

Fig. 12. The average friction factor of all cases with Reynolds number for $Q=100 \mathrm{~W} / \mathrm{cm}^{2}$.

We also notice that the average friction factor decreases by small values in the first, third, and fourth cases compared to the second case, where we find that the average friction factor decreases by considerable values. It can be concluded that the microchannels that contain the ribs are under the influence of the average friction factor compared to the micro-channel that does not contain the ribs where the effect is the average friction factor is minimal, unlike what we found in the second case.

\section{Conclusions}

The present study deals with three-dimensional numerical simulations of the position influence of parallelogram ribs in micro-channel on the thermal exchange using a diamond-water nanofluid as a coolant with $5 \%$ volume fraction of diamond nanoparticles. The obtained results confirm that

- With the increase of Reynolds number (Re) for all cases, we found that the temperature on the heated bottom wall decreases, also we find the temperature values on the heated bottom on the second case are low compared to the other studied cases.

- For the Reynolds number ranging from 200 to 400 , we find that the parallelogram ribs position of micro-channels in case 3 is effective compared to the parallelogram ribs position of micro-channel in case 4 .

- Increasing the flow velocity reduces the thermal resistance and the friction factor simultaneously in all cases. It shows the friction factor of the micro-channels with parallelogram ribs in case 2 is higher than those in other cases. And also, the micro-channels of the first case (without ribs) have the highest value of the thermal resistance, while we find the least resistance found in case 2 .

- In this study, the position of the parallelogram ribs in the second case provides much better thermal performance than the other cases, as confirmed by our study, as we found the maximum value for the Nusselt number and the average heat exchange coefficient in this case, and therefore the design of the microchannel in the second case can help in cooling the components electronically and could be improved in the future. 


\section{NOMENCLATURE}

\section{Symbols:}

$\mathrm{A}_{\mathrm{w}}$ : inner wall or fluid contact Re: Reynolds number surface area, $\mathrm{m}^{2} \quad \mathrm{~T}$ : $\quad$ temperature, $\mathrm{K}$

$\mathrm{C}_{\mathrm{p}}$ : specific heat of the fluid, $\mathrm{J} / \mathrm{kg} \cdot \mathrm{K} \quad \mathrm{T}_{\mathrm{m}}$ : mass-average temperature of the cool-

$\mathrm{D}_{\mathrm{h}}$ : hydraulic diameter of microchannel, $\mathrm{m}$

$\mathrm{H}$ : height, $\mathrm{m}$

$\mathrm{H}_{\mathrm{c}}$ : micro-channel height, $\mathrm{m}$

$\mathrm{h}_{\text {ave }}$ : average heat transfer coefficient , $\mathrm{W} \mathrm{m} \mathrm{m}^{-2} \mathrm{~K}^{-1}$

$\mathrm{k}$ : thermal conductivity, $\mathrm{Wm}^{-1} \mathrm{~K}^{-1}$

$\mathrm{L}$ : micro-channel length, $\mathrm{m}$

$\mathrm{N}$ : number of micro-channels

$\mathrm{p}$ : pressure, $\mathrm{Pa}$

$\mathrm{Q}$ : heat flux dissipated in the chip,W ant, $\mathrm{K}$

$\mathrm{T}_{\max }$ : maximum temperature on the bottom wall, $\mathrm{K}$

$\mathrm{T}_{\mathrm{w}}$ : area-weighted temperature of the channel wall surface, $\mathrm{K}$

$\mathrm{x}, \mathrm{y}, \mathrm{z}$ : cartesian coordinate, $\mathrm{m}$

$\mathrm{u}, \mathrm{v}, \mathrm{w}$ : velocity components, $\mathrm{m} \mathrm{s}^{-1}$

$\mathrm{W}$ : width, $\mathrm{m}$

$\mathrm{W}_{\mathrm{c}}$ : micro-channel width, $\mathrm{m}$

\section{Indices :}

c: micro-channel

$\mathrm{f}$ : base fluid (water)

in: inlet

$\mathrm{n}$ : outer normal coordinate at interface between the wall and fluid

nf: nanofluid

out: outlet

s: solid

\section{Greek letters:}

$\rho:$ coolant density, $\mathrm{kg} / \mathrm{m}^{3}$

$\mu$ : dynamic viscosity of coolant, $\mathrm{kg} / \mathrm{m} \cdot \mathrm{s}$

$\varphi$ : volume fraction

$\alpha$ : thermal diffusivity, $\mathrm{m}^{2} \cdot \mathrm{s}^{-1}$

\section{References}

[1] W. Hongtao, C. Zhihua, G. Jianguo: Applied Thermal Engineering, 107 (2016) 870-879.

[2] M. Gholami, M. R. Nazari,M.H. Talebi,F. Pourfattah,O. A. Akbari,D. Toghraie:Chinese Journal of Chemical Engineering, 28 (2020) 643-659.

[3] R. Mashayekhi, H. Arasteh, D. Toghraie, S. H. Motaharpour, A. Keshmiri,M. Afrand: Computers \& Mathematics with Applications, 79 (2020) 2203-2215.

[4] S. V. Jadhav, P. M. Pawar, B. P. Ronge: Journal of Chemical Product and Process Modeling, 14 (2018) 1934-2659.

[5] W. He,D. Toghraie,A. Lotfipour,F. Pourfattah,A. Karimipour,M. Afrand: International Communications in Heat and Mass Transfer, 110 (2020) 104440.

[6] M. Miansari, H. Aghajani, M. Zarringhalam, D. Toghraie: Journal of Thermal Analysis and Calorimetry (2020).

[7] R. Bouakkaz, Y. khelili, A. Abdelouahed: Metallurgical and Materials Engineering, 25 (2019) 225-236

[8] Y. Peng, M. Zarringhalam, M. Hajian, D. Toghraie, S. J. Tadi, M. Afrand: Journal of Molecular Liquids, 295 (2019) 111721. 
[9] E. Khodabandeh, R. Boushehri, O. A. Akbari, S. Akbari, D. Toghraie: Journal of Thermal Analysis and Calorimetry (2020).

[10] N. Shirani, D. Toghraie, S. Rostami: Journal of Thermal Analysis and Calorimetry (2020).

[11] M. Mehdi, H. Afshin, M. Morteza, T. Davood: Journal of Thermal Science (2020).

[12] M. Jamali, D. Toghraie: Journal of Thermal Analysis and Calorimetry, 139 (2020) 685-699.

[13] A. Abasi Varzaneh, D. Toghraie, A. Karimipour: Journal of Thermal Analysis and Calorimetry, 139 (2020) 701-720.

[14] F. Pourfattah, M. Sabzpooshani, D. Toghraie, A. Asadi: Journal of Thermal Analysis and Calorimetry (2020).

[15] W. He,R. Mashayekhi,D. Toghraie,O. AliAkbari,Z. Li,I. Tlili:International Communications in Heat and Mass Transfer, 117 ( 2020) 104700.

[16] H. Bazdar, D. Toghraie, F. Pourfattah, O.A. Akbari, H.M. Nguyen, A. Asadi: Journal of Thermal Analysis and Calorimetry, 139 (2020) 2365-2380.

[17] S. Fohanno, G. Polidori, C. Popa: Nanofluides et transfert de chaleur par convection naturelle, Université de reims champagne-Ardenne, France, 2012.

[18] K. Khanafer, K. Vafai, M. Lightstone: International Journal Heat and Mass Transfer,49 (2003)3639-3653.

[19] P. Gunnasegaran, N.H. Shuaib, H.A. Mohammed, M.F. Abdul Jalal, E. Sandhita: Fluid Dynamics, Computational Modeling and Applications, (2012) 287-326.

[20] T.C. Hung, W.M. Yan, X.D. Wang, C.Y. Chang: International Journal of Heat and Mass Transfer, 55 (2012) 2559-2570.

[21] M.K. Moraveji, R.M. Ardehali, A. Ijam: International Communications in Heat and Mass Transfer, 40 (2013)58-66.

[22] X. Gongnan, L. Shian, S. Bengt, Z. Weihong, L. Haibin: Numerical Heat Transfer, Part A, 65 (2014) 107-126.

[23] L. Chai, L. Wang, X. Bai: International Journal of Heat and Mass Transfer, 128 (2019) 634-648.

[24] L. Chai, G. Xia, L. Wang, M. Zhou, Z. Cui Z: International Journal of Heat and Mass Transfer, 62 (2013) 741-751.

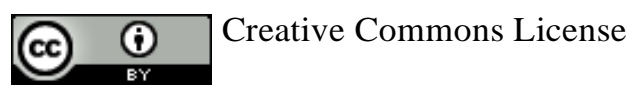

This work is licensed under a Creative Commons Attribution 4.0 International License. 